studies also demonstrated that the suppression of KLF-5 by silencing RNA resulted in a reduction of NFאB1 mRNA in IEC6 cells stimulated with lipopolysaccharide, indicating that KLF-5 is an upstream regulator for NFאB1 mRNA expression in IEC6 cells. ${ }^{7}$ Taken together, it is most likely that the upregulation of KLF-5 mRNA expression might lead to the enhanced expression of NFкB1 mRNA in BM CD34+ cells, but not vice versa, in RA. In addition, the upregulation of KLF-5 mRNA as well as NFkB1 mRNA in RA BM CD34+ cells might result in their abnormal capacities to differentiate into fibroblast-like cells.

In summary, we demonstrate that KLF-5 mRNA expression is upregulated in BM CD34+ cells independently of the systemic inflammation or treatment regimen in RA. Although it is strongly suggested that KLF-5 might be an upstream regulator of NFKB1 mRNA in BM CD34+ cells, further studies to explore the mechanism of abnormal expression of KLF- 5 mRNA in BM CD34+ cells would be important for a complete understanding of the pathogenesis of RA.

\section{S Hirohata, ${ }^{1}$ Y Miura, ${ }^{2}$ T Tomita ${ }^{3}$ H Yoshikawa ${ }^{3}$}

${ }^{1}$ Department of Rheumatology and Infectious Diseases, Kitasato University School of Medicine, Kanagawa, Japan; ${ }^{2}$ Faculty of Health Sciences, Kobe University School of Medicine, Kobe, Japan; ${ }^{3}$ Department of Orthopedic Surgery, Osaka University Medical School, Osaka, Japan

Correspondence to: Dr S Hirohata, Department of Rheumatology and Infectious Diseases, Kitasato University School of Medicine, 1-15-1 Kitasato, Sagamihara, Kanagawa 228-8555 Japan; shunsei_tenpoint@yahoo.co.jp
Acknowledgements: The authors wish to thank Tamiko Yanagida, PhD, for her technical assistance.

Funding: This work was supported by a grant-in-aid from the Health Science Research grant from the Ministry of Health and Welfare of Japan and a grant from Astellas Pharma Inc, Tokyo, Japan.

Competing interests: None.

Accepted 2 September 2008

Ann Rheum Dis 2009;68:763-764. doi:10.1136/ard.2008.099135

\section{REFERENCES}

1. Hirohata S, Yanagida T, Nagai T, Sawada T, Nakamura H, Yoshino S, et al. Induction of fibroblast-like cells from CD34(+) progenitor cells of the bone marrow in rheumatoid arthritis. J Leukoc Biol 2001;70:413-21.

2. Hirohata S, Miura Y, Tomita T, Yoshikawa H, Ochi T, Chiorazzi N. Enhanced expression of mRNA for nuclear factor kappaB1 (p50) in CD34+ cells of the bone marrow in rheumatoid arthritis. Arthritis Res Ther 2006:8:R54.

3. Shindo T, Manabe I, Fukushima Y, Tobe K, Aizawa K, Miyamoto S, et al. Krüppel-like zinc-finger transcription factor KLF5/BTEB2 is a target for angiotensin II signaling and an essential regulator of cardiovascular remodeling. Nat Med 2002;8:856-63.

4. Nagai R, Suzuki T, Aizawa K, Shindo T, Manabe I. Significance of the transcription factor KLF5 in cardiovascular remodeling. J Thromb Haemost 2005;3:1569-76.

5. Aizawa K, Suzuki T, Kada N, Ishihara A, Kawai-Kowase K, Matsumura T, et al. Regulation of platelet-derived growth factor-A chain by Krüppel-like factor 5: new pathway of cooperative activation with nuclear factor-kappa B. J Biol Chem 2004;279:70-6.

6. Ohba T, Takase Y, Ohhara M, Kasukawa R. Thrombin in the synovial fluid of patients with rheumatoid arthritis mediates proliferation of synovial fibroblast-like cells by induction of platelet derived growth factor. J Rheumatol 1996;23:1505-11.

7. Chanchevalap S, Nandan MO, McConnell BB, Charrier L, Merlin D, Katz JP, et al. Krüppel-like factor 5 is an important mediator for lipopolysaccharide-induced proinflammatory response in intestinal epithelial cells. Nucl Acids Res 2006;34:1216-23.

\title{
Corrections
}

An author affiliation was incorrect in the an article published in March 2008 (Jónsdóttir T, Gunnarsson I, Risselada A, et al. Treatment of refractory SLE with rituximab plus cyclophosphamide: clinical effects, serological changes, and predictors of response. Ann Rheum Dis 2008;67:330-4). The correct affiliation for all authors is Department of Rheumatology, The Karolinska University Hospital, The Karolinska Institutet, Stockholm, Sweden.

doi:10.1136/ard.2007.079095.corr1

An author name and affiliation was incorrect in the an article published in October 2008 (Lu TY$\mathrm{T}$, Jónsdóttir $\mathrm{T}$, van Vollenhoven RF, et al. Prolonged B-cell depletion following rituximab therapy in systemic lupus erythematosus: a report of two cases. Ann Rheum Dis 2008;67:1493-4). The second author's name is spelt Jónsdóttir, not Jonsdottir as given in the article. The correct affiliation for all authors is Department of Rheumatology, The Karolinska University Hospital, The Karolinska Institutet, Stockholm, Sweden.

doi:10.1136/ard.2008.091124.corr1

The article Song IH, Althoff CE, Hermann KG, Scheel AK, Knetsch T, Schoenharting M, et al. Knee osteoarthritis. Efficacy of a new method of contrast-enhanced musculoskeletal ultrasonography in detection of synovitis in patients with knee osteoarthritis in comparison with magnetic resonance imaging. Ann Rheum Dis 2008;67:19-25 was originally published in print with an incorrect digital object identifier (doi) of 10.1136/ard.2007.067462. It has been updated online with the correct doi: 10.1136/ard.2006.067462. We apologise for any inconvenience caused. 